\title{
Anti-oxidative metabolite comparison between two phenotypes of Celastrus hindsii Benth
}

Van Huy Nguyen ${ }^{1 *}$, Thanh Loan Pham ${ }^{1}$, Quang Trung Nguyen ${ }^{2}$

${ }^{1}$ Institute of Applied Research and Development, Hung Vuong University, Phu Tho, Vietnam

${ }^{2}$ Faculty of Agriculture, Hung Vuong University, Phu Tho, Vietnam

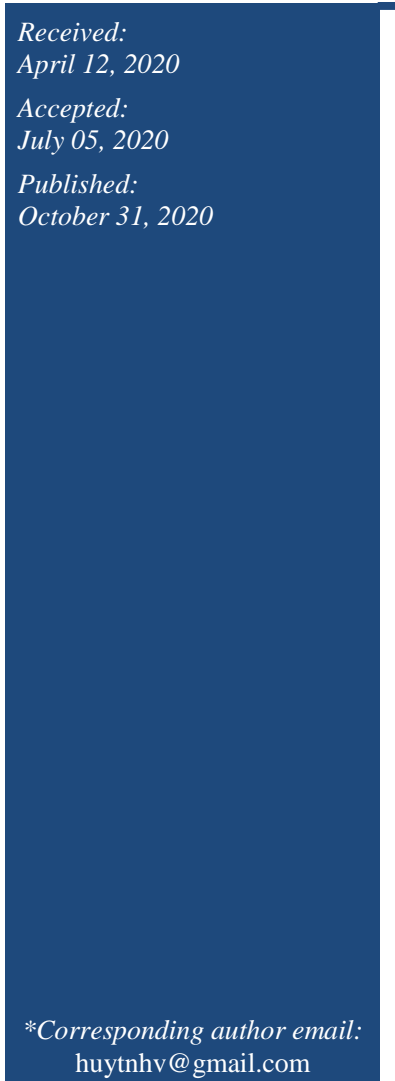

huytnhv@gmail.com

\begin{abstract}
Celastrus hindsii Benth. is an evergreen twining shrub that has been used for generations in Northern Vietnam for diseased treatment relating to ulcers, tumors, and inflammation due to its bioactive compounds. The narrow leaf and broad leaf phenotypes have raised concerns about their comparatively biochemical quality, which is the determinant of their uses for medicinal purposes. The study aimed to investigate the concentration of important anti-oxidative metabolites between narrow leaf and broad leaf phenotypes using spectrophotometric method. The results showed that BL had a significantly higher level of $\alpha$-tocopherol, flavonoid, phospholipid, and possibly glutathione (based on an air-dry weight and protein basis). Stress biomarkers such as proline and malondialdehyde were elevated in NL, indicating their roles in response to stress. In contrast, the enzyme and metabolite increase in NL may be associated with tissue degradation. BL of $C$. hindsii, which contains more diverse and superior concentrations of essential phytochemicals and pharmaceutically related proteins, should be positioned as an important commercial source for natural drug development.
\end{abstract}

Keywords: Secondary metabolite, Antioxidant, $\alpha$-tocopherol, Flavonoid, Morphological variation

\section{How to cite this:}

Nguyen VH, Pham TL and Nguyen QT, 2020. Anti-oxidative metabolite comparison between two phenotypes of Celastrus hindsii Benth. Asian J. Agric. Biol. 8(4): 501510. DOI: https://doi.org/10.35495/ajab.2020.04.223

This is an Open Access article distributed under the terms of the Creative Commons Attribution 3.0 License. (https://creativecommons.org/licenses/by/3.0), which permits unrestricted use, distribution, and reproduction in any medium, provided the original work is properly cited.

\section{Introduction}

Plants exposed to adverse abiotic stresses usually display a range of morphogenetic and biochemical responses to redirecting growth and metabolism. Plants may alter their morphological characteristic through a mechanism of inhibiting cell elongation, stimulating cell division, and altering cell differentiation status (Purugganan, 2019). These alterations may be reflected in conventional molecular processes such as increasing reactive oxygen species (ROS) production, modifying metabolism and phytohormone transport, and signaling responses (Fichman et al., 2019). The underlying mechanism is that under oxidative damage, plants alter their morphological and biochemical activities to mitigate stress exposure and enhance repair of damaged systems. As a result, the stress tolerance of plants may also be boosted through plant responses, such as antioxidant defenses (Sharma and Kaur, 2018). 
To minimize the exposure to unfavorable stresses, plants have altered their morphological adaptations and biochemical mechanisms. Several studies on plants have revealed differential morphological responses such as decreased root, shoot or leaf elongation (Nagayama et al., 2019), increased leaf thickness and reduced specific leaf area (Mediavilla et al., 2018) against stresses such as UV-B radiation, toxic heavy metals, nutrient-deficiencies and hypoxia (de la Cruz Jiménez et al., 2019). Protective mechanisms against the action of activated oxygen species exist, and central to these mechanisms include the action of antioxidants (Kamiloglu et al., 2016). Given that plant cells and organelles are exposed to ROS, plants have changed biological processes to prevent ROS formation and scavenge ROS by the accumulation of low molecular weight antioxidants such as ascorbic acid, glutathione, $\alpha$-tocopherols, amino acids (e.g., proline), sugars, carotenoids, and quinic acid derivatives. Along with the accumulation of these anti-oxidative metabolites, various other kinds of specialized metabolites are also produced in response to stresses (Nakabayashi and Saito, 2015).

$C$. hindsii is used in traditional Vietnamese medicines and widely grown in Northern Vietnam in household gardens and nurseries and used as dry leaves, chopped dry stems, branches, or roots (The Asian Foundation, 2012). Leaf features are highlighted by broad rectangular elliptic and narrowly ovate-elliptic leaf blades (broad and narrow leaf). However, these features have not yet been identified phenotypic responsive to stress, i.e., induced morphogenetic responses. In plants, phenotypic variation can be explained based on the diverse geographical origins of the variants and local human selection. As a result, only the plant part of interest is selected, and potential ecotypes and botanical varieties are likely to form (Purugganan, 2019). The C. hindsii collection in Vietnam is characterized by several phenotypic variations for traits of interest, such as broadleaf blade variant in Hoa Binh province, which has been chosen for cultivation because it provides larger biomass for trades. The finding is worth paying attention to as it is in line with the purpose of ex-situ conservation, which is designed to preserve sufficient biological diversity of important traits, especially for commercial medicinal plants.

Recently, studies of $C$. hindsii have mainly focused on phytochemical investigations, regardless of the biological variation of different germplasms or leaf morphological variants (Yao-Haur Kuo et al., 1995;
Ly et al., 2006; Hu et al., 2013; 2014). Therefore, the relationship between morphological characteristics and bioactive compounds content has already been discovered (Khanna et al., 2014; Fu et al., 2016). Thus, it is worth investigating the mechanisms by which leaf variations affect plant ecotypes in a comparative study of secondary metabolites accumulated in leaf extracts of C. hindsii.

The purpose of this comparative study was to determine the amount of anti-oxidative metabolites, including proline, glutathione, tocopherol, flavonoid, and phospholipid in two forms of leaf phenotypes: narrow leaf (NL) and broadleaf (BL) variants of $C$. hindsii. Malondialdehyde, a product of lipid peroxidation, will be measured because it is also a biomarker measurement of stresses. It is expected that information from antioxidants and stress biomarkers will be supportive to select appropriate populations, which is better in stress tolerance and pharmaceutical properties, for commercial utilization of medicinal plant $C$. hindsii.

\section{Material and Methods}

\section{Plant material}

C. hindsii leaves (two broadleaf plants and two narrow-leaf plants) were collected from two adjacent gardens, which are similar in soil and fertilized conditions in Phu Tho province. The specimens were classified into the two morphogenetic groups: narrowleaf and broadleaf and authenticated by Dr. Pham Thanh Loan (Institute of Applied Research and Development, Hung Vuong University, Vietnam). The classification into small leaf plants and broadleaf plants was based on leaf length, leaf width, leaf thickness, and yield. Leaves were manually harvested from mature plants, cleaned and immediately protected away from moisture and direct sunlight in silica filled sealed plastic bags in the field, before shipment. Air-dried leaves after transporting were store in $-80^{\circ} \mathrm{C}$ freezer. Air-dried leaf material was weighed using an electronic balance (Sartorious, Quintix224-1S, Germany, accuracy $\pm 0.0001 \mathrm{~g}$ ) and sliced into thin pieces $\left(1-2 \mathrm{~mm}^{2}\right)$ for enzyme and metabolite extraction and extracted in various specific buffers using a cold pestle and mortar.

Air dry weights and protein basis were used to standardize the quantity of enzymes and metabolites. Dry weight was also measured to quantify the water content using air-dried leaf tissues in the oven at $65^{\circ} \mathrm{C}$ overnight. The total evaporable moisture content and 
water content percentage $(\mathrm{P})$ of tissue were calculated with the formula:

$\mathrm{P}=(\mathrm{ADW}-\mathrm{DW}) / \mathrm{ADW} \times 100$ where ADW - Air dry weight; DW - Dry weight

\section{Protein content assay}

Protein was assayed using a commercial assay kit (Bio-Rad). The Bio-Rad protein assay is highlighted by the change in the distinguished color of a dye due to various protein concentrations. The absorbance maximum change from $465 \mathrm{~nm}$ to $595 \mathrm{~nm}$ when the binding of protein occurs with an acidic solution of Coomassie Brilliant Blue G-250. Lambert-Beer's-Law with the appropriate ratio of dye volume to sample concentration results in accurate quantification of total soluble protein. $5 \mu \mathrm{l}$ of enzyme/metabolite solution and $995 \mu \mathrm{l}$ of the diluted dye reagent (Bio-Rad reagent diluted 1:5) were added to clean dry test tubes $(2 \mathrm{ml})$ and mixed thoroughly with a vortex. After $5 \mathrm{~min}$, absorbance was determined at $595 \mathrm{~nm}$ in glass cuvettes. The blank consisted of the diluted dye reagent. Cuvettes were rinsed and cleaned between measurements with reagent grade water followed by acetone to ensure the removal of all blue dye complex.

\section{Antioxidant assays}

Proline

Aqueous sulphosalicylic acid was used during selective extraction. Proteins considered as interfering materials were precipitated as a complex, and others were mainly detached by captivation as a complex of protein-sulphosalicylic acid. The extracted proline is reacted with ninhydrin to form the blue chlorophore in acidic conditions and read at 520nm(Bates et al., 1973). The assay mixture was composed of the following constituents: Sulfosalicylic acid 3\%; Toluene; and ninhydrin in glacial acetic acid: $1.25 \mathrm{~g}$ ninhydrin dissolved in $30 \mathrm{ml}$ glacial acetic acid and 20 $\mathrm{ml} 6 \mathrm{~mol} / \mathrm{L}$ phosphoric acid.

$100 \mathrm{mg}$ of plant materials were ground with a mortar and pestle in liquid-formed nitrogen and extracted in $3 \%$ sulfosalicylic acid. Then mixtures were filtered and made up to $2 \mathrm{ml}$. This $2 \mathrm{ml}$ of filtrate was reacted with $2 \mathrm{ml}$ acid ninhydrin in glacial acetic acid, and the mixture was boiled in a water bath for one $h$, then the reaction quickly terminated in ice. The reaction mixture was then extracted with $3 \mathrm{ml}$ toluene followed by vortex and left at room temperature for $30 \mathrm{~min}$ until the separation of the two phases. A toluene blue layer appeared and ready to be read by a spectrophotometer (Biochrom Libra S12 UV/Vis) at $520 \mathrm{~nm}$.

\section{Glutathione (GHS)}

The determination of the total concentration of glutathione was performed in a kinetic reaction according to the oxidation of GHS to GSSG by the Ellman reagent DTNB (5,5'-dithiobis-(2-nitrobenzoic acid)) to produce a conjugate and TNB anion that can be detected by UV/Vis absorbance. Instead of a single determination of how much DTNB reacts with GSH, the rate of TNB production is measured over a set time, as that is proportional to the initial amount of GSH (Forman et al., 2009). The assay mixture was composed of the following constituents: Trichloroacetic acid (TCA) 5\%, and phosphate buffer (pH8.0) 0.2 M.

$100 \mathrm{mg}$ of fresh leaf tissue was ground by mortar and pestle to a fine powder in liquid nitrogen and then treated in $2 \mathrm{ml}$ of TCA (5\%). The mixtures were centrifuged at $12,000 \mathrm{~g}$ for $15 \mathrm{~min}$ in cold ice temperature $\left(4^{0} \mathrm{C}\right)$, and the supernatant was taken. After deproteinization, $2.9 \mathrm{ml}$ of Ellman's reagent (2

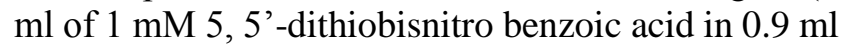
of $0.2 \mathrm{M}$ phosphate buffer $\mathrm{pH}$ 7.0) was added to react with the supernatant. The absorbance of the yellow product was read at $412 \mathrm{~nm}$ and $340 \mathrm{~nm}$ in a spectrophotometer (Biochrom Libra S12 UV/Vis). Pure GSH was used as a standard for establishing the calibration curve.

\section{Tocopherol}

This method used the reaction, which was based on the reduction by tocopherol of ferric ions to ferrous ions, which then forms a red color complex with $\alpha, \alpha^{\prime}-$ dipyridyl reagent (Kivcak and Akay, 2005). The assay mixture was composed of the following constituents: Absolute ethanol; Xylene (100\%); $\mathrm{H}_{2} \mathrm{SO}_{4} 0.1 \mathrm{~N} ; \alpha, \alpha$ - dipyridyl reagent: $1.2 \mathrm{gm}$ of dipyridyl reagent was weighed and dissolved in ethanol, and the final volume was made up to 1 litter, then kept in a dark place for next use. Ferric chloride $\mathrm{FeCl}_{3}(0.3 \%)$ : dissolve $0.3 \mathrm{~g}$ in $100 \mathrm{ml}$ of absolute ethanol.

$100 \mathrm{mg}$ of fresh leaf tissue was ground to a fine powder in liquid nitrogen and then treated in $2 \mathrm{ml}$ of $0.1 \mathrm{~N} \mathrm{H}_{2} \mathrm{SO}_{4}$. Then mixtures were incubated at room temperature overnight and filtered. Afterward, extracts $(1.5 \mathrm{ml})$ were transferred to a $15 \mathrm{ml}$ tube, then $1.5 \mathrm{ml}$ methanol and $1.5 \mathrm{ml}$ xylene were added. The mixture was vortexed for about 1 minute to allow separation. $1.0 \mathrm{ml}$ of the supernatant was collected and transfer to new tubes, then $\alpha, \alpha^{\prime}$ - dipyridyl (1.2gram in $100 \%$ ethanol) were added to the mixture. Next, $\mathrm{FeCl} 3$ (3\%) was added, and solutions were kept for 1 minute. The 
absorbance of the solutions was read at $520 \mathrm{~nm}$ and $460 \mathrm{~nm}$ using a spectrophotometer (Biochrom Libra S12 UV/Vis). During their preparation, all solutions were stored away from the light. $\alpha$-tocopherol standard was dissolved in xylene in a concentration range of 0 $320 \mu \mathrm{g} / \mathrm{ml}$, and a calibration curve was calculated.

\section{Flavonoids}

The vanillin reacts with an aromatic aldehyde with the meta-substituted ring of flavonoids to yield a red adduct, according to Swain and Hillis (1959). The assay mixture was composed of the following constituents: Vanillin: 1\% dissolved in 70\% sulphuric acid; Absolute Methanol: Water (2:1); and Absolute Methanol: Water (1:1).

$100 \mathrm{mg}$ of leaf samples were ground with a mortar and pestle in liquid nitrogen and extracted in $1.5 \mathrm{ml}$ methanol: water (ratio 2:1). The centrifuged $(12,000$ g) and collected supernatant were transferred to a new tube $(15 \mathrm{ml})$. The solid phase was extracted again in $1.5 \mathrm{ml}$ of methanol: water $(1: 1)$. Centrifuged $(12,000$ $\mathrm{g}$ ), the supernatant collected and combined with the first extract. The combined extract was evaporated to dryness with slight heat using an incandescence bulb lamp in the fume hood. $4 \mathrm{ml}$ of working vanillin reagent was added to the dry extract and boiled for 15 min. The sample was then left on a bench to cool down, and the absorbance at $340 \mathrm{~nm}$ was read $(340 \mathrm{~nm}$ for flavones and flavanones) (Morina et al., 2015) by a spectrophotometer (Biochrom Libra S12 UV/Vis). The color became dark black due to a high level of flavonoids; therefore, the solution was diluted 1:10 before reading.

\section{Phospholipids}

Phospholipids in lipid extracts were estimated by phosphorous release and determined through acidic digestion. The assay mixture was composed of the following constituents: Chloroform: Methanol (1:1); concentrated sulphuric acid; Nitric acid $(5 \mathrm{~N})$ : slowly add $318.522 \mathrm{ml}$ of $70 \%$ Nitric acid to $250 \mathrm{ml}$ deionized water. Adjust the final volume of solution to $1000 \mathrm{ml}$ with deionized water; Sodium hydroxide (1N): dissolve $50 \mathrm{~g}$ of $\mathrm{AR} \mathrm{NaOH}$ in 1 liter distilled water. Phosphorous reagent A: Add together $76.80 \mathrm{~g}$ Ammonium Molybdate dissolved in $200 \mathrm{ml}$ distilled water, and $1.755 \mathrm{~g}$ Antimony Potassium Tartrate dissolved in $100 \mathrm{ml}$ distilled water. Add carefully a mixture of $500 \mathrm{ml}$ of distilled water and $896 \mathrm{ml}$ concentrated AR grade sulphuric acid. Make up to 2 liters of distilled water.
The resulting solution should be clear and colorless, and it will keep for a long time but should be stored in a cool place. Look for cloudiness or precipitation when it is off. Phosphorous reagent B: Dissolve $1.70 \mathrm{~g}$ ascorbic acid in $100 \mathrm{ml}$ distilled water (this keeps only for $48 \mathrm{~h}$ ) and add $50 \mathrm{ml}$ of reagent A just before using in tests. Make up to $200 \mathrm{ml}$ with distilled water just before use. This final reagent is unstable and should be prepared fresh every day.

$100 \mathrm{mg}$ of leaf samples were ground with a mortar and pestle in liquid nitrogen and extracted in $2 \mathrm{ml}$ chloroform: methanol (1:1). The volume was evaporated to dryness with slight heat using an incandescence bulb lamp in the fume hood. $1 \mathrm{ml}$ sulphuric acid was added to the dry extract, and a brown color allowed developing. 2-5 drops of Nitric acid $(5 \mathrm{~N})$ were added until a colorless solution was obtained. The samples were then added to $2 \mathrm{ml}$ of distilled water. The final mixture of the sample included: $2 \mathrm{ml}$ sample from before, $1 \mathrm{ml} 1 \mathrm{~N} \mathrm{NaOH}, 10$ $\mathrm{ml}$ distilled water and $2 \mathrm{ml}$ phosphorous reagent $\mathrm{B}$; which was heated at $60^{\circ} \mathrm{C}$ for $10 \mathrm{~min}$ and cooled down to room temperature for reading (at $880 \mathrm{~nm}$ ) by a spectrophotometer (Biochrom Libra S12 UV/Vis, UK).

\section{Malondialdehyde (MDA)}

Malondialdehyde is one of the end products that resulted from the breakdown of certain lipid peroxidation products. At low $\mathrm{pH}$ and elevated temperatures, MDA reacts with thiobarbituric acid (TBA), producing a red fluorescent 1:2 MDA: TBAR (thiobarbituric acid-reactive-substances) adduct. The assay mixture was composed of the following constituents: Trichloroacetic acid (TCA) $0.1 \%$; and trichloroacetic acid $(0.1 \%)+$ Thiobarbatate (TBARS) $0.5 \%$.

$100 \mathrm{mg}$ of leaf samples were ground with a mortar and pestle in liquid nitrogen and extracted in $2 \mathrm{ml} 0.1 \%$ (w/v) TCA. The resulting solution was transferred with a pasteurized pipette to $2 \mathrm{ml}$ Eppendorf tubes and centrifuged at 12,000 (g) for $5 \mathrm{~min} .1 \mathrm{ml} \mathrm{20 \% (w/v)}$ TCA containing $0.5 \%(\mathrm{w} / \mathrm{v})$ thiobarbituric acid was added to $1 \mathrm{ml}$ plant tissue sample in a $10 \mathrm{ml}$ test tube. The reaction mixtures were vortexed thoroughly and incubated at $95^{\circ} \mathrm{C}$ in a water bath for $30 \mathrm{~min}$. The reaction was terminated by placing sample tubes in an ice bath. The mixture was centrifuged again for $10 \mathrm{~min}$ at $12,000 \mathrm{~g}$ and absorbance recorded at $532 \mathrm{~nm}$ and $600 \mathrm{~nm}$ by a spectrophotometer (Biochrom Libra S12 
UV/Vis). The control blank was $1 \mathrm{ml} 0.1 \%(\mathrm{w} / \mathrm{v}) \mathrm{TCA}$ and $4 \mathrm{ml} 20 \%(\mathrm{w} / \mathrm{v})$ TCA containing $0.5 \%(\mathrm{w} / \mathrm{v})$ thiobarbituric acid. One absorbance unit $(532 \mathrm{~nm})$ was equivalent to $155 \mathrm{mmol} / \mathrm{l} \mathrm{MDA}$ in the sample.

\section{Statistical analysis}

Enzyme and metabolites experiments were designed to ensure the inclusion of a sufficient number of replicates for statistical analysis. Statistical analysis was conducted on the data using means, standard errors, one-way analysis of variance (ANOVA). Duncan Test was applied for further statistical analysis following the rejection of the null hypothesis by ANOVA. This method allowed a comparison of every possible pair of means using a single level of significance $(\mathrm{P}=0.05)$.

\section{Results}
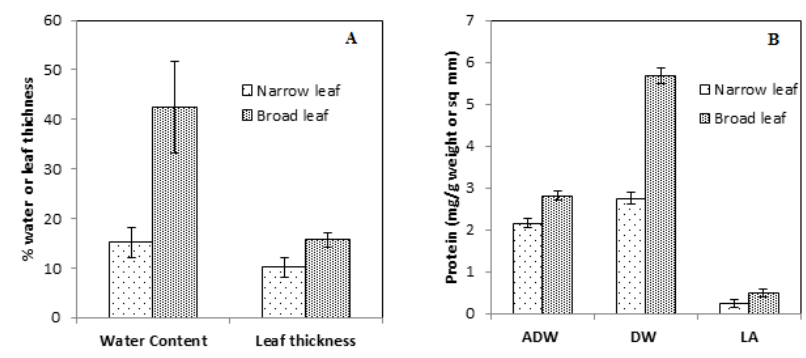

Figure-1. Percentage water and leaf thickness (A), protein content based on air-dried weight (ADW), dry weight $(D W)$ and leaf area (LA) $(B)$ in narrow leaf (NL) and broadleaf (BL)

\section{Protein content}

Water content, leaf thickness, and protein content based on air-dried weight, dry weight, and leaf area were determined in NL and $\mathrm{BL}$ of $C$. hindsii. The results are shown in Figure 1. Although the variants were cultivated in the same area, the difference in some parameters above was significant. There was a significant difference in the percentage of water contained in NL and BL. BL contains $42.53 \%$ water, while there was much lower water content in NL at only $15.14 \%$. Also, the thickness, length, and width of the leaf blade in BL were all significantly different from NL.

\section{Proline and glutathione}

Proline content increased significantly in NL with $12.71 \pm 0.77(\mu \mathrm{mol} / \mathrm{g}$ ADW) and was substantially lower in BL with $9.7 \pm 0.78(\mu \mathrm{mol} / \mathrm{g} \mathrm{ADW})$. However, there was not a statistically significant difference in proline content between NL and BL on a protein basis (Figure 2). Although glutathione content in BL was measured higher than that in NL on the ADW basis, there was not a statistically significant difference between NL and BL extracts on both ADW and protein basis (one-way ANOVA and Duncan Test).
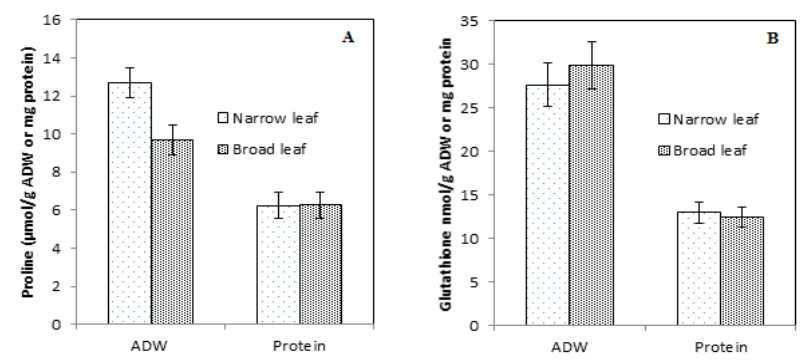

Figure-2. Proline (A) and glutathione (B) content on a protein basis and an ADW basis in NL and BL extracts. Mean values $\pm(n=8)$. Mean values $\pm(n=8)$. Mean values $\pm(n=8)$. Data and results were based on one-way ANOVA and Duncan Test.

\section{Tocopherol and flavonoid}

Both tocopherol and flavonoids in BL extract are significantly higher than those in NL extracts (Figure $3)$.
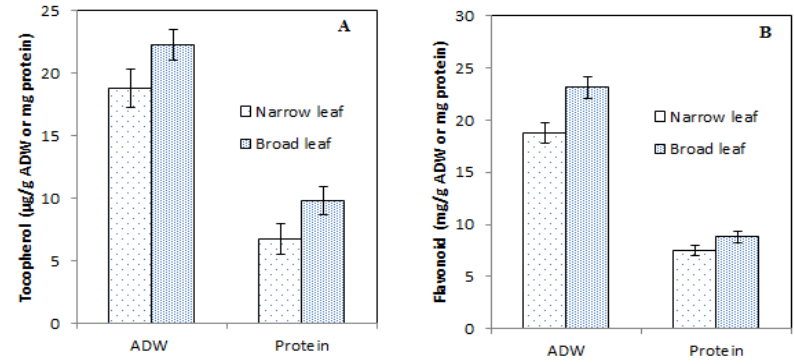

Figure-3. Tocopherol (A) and flavonoid (B) content on a protein basis and a dry weight basis in NL and BL extracts. Mean values $\pm(n=8)$. Mean values \pm $(n=8)$. Data and results were based on one-way ANOVA and Duncan Test.

These differences are statistically significant (one-way ANOVA and Duncan Test). The tocopherol content expressed on $\mathrm{ADW}$ and protein bases, varied from $18.81 \pm 1.5(\mu \mathrm{g} / \mathrm{g} \mathrm{ADW})$ or $6.77 \pm 1.2(\mu \mathrm{g} / \mathrm{mg}$ protein $)$ on $\mathrm{NL}$; to $22.29 \pm 1.23(\mu \mathrm{g} / \mathrm{g} \mathrm{ADW})$ or $9.79 \pm 1.1$ $(\mu \mathrm{g} / \mathrm{mg}$ protein) on BL respectively. In the same way, flavonoids content increased significantly from 18.75 $\pm 0.96(\mathrm{mg} / \mathrm{g} \mathrm{ADW})$ or $7.43 \pm 0.49(\mathrm{mg} / \mathrm{mg}$ protein $)$ in $\mathrm{NL}$ to $23.16 \pm 1.03(\mathrm{mg} / \mathrm{g} \mathrm{ADW})$ or $8.78 \pm 0.52$ 
(mg/mg protein) in BL. From the data, both flavonoids and tocopherol concentrations are lower if measured based on protein content but still significantly different.

\section{Phospholipid and malondialdehyde (MDA)}

It is apparent from Figure 4 that phospholipid content in BL is statistically elevated on ADW with a statistically significant difference. Phospholipids content increased from $6.25 \pm 0.7(\mu \mathrm{g} / \mathrm{g}$ ADW) in NL to $8.23 \pm 0.69(\mu \mathrm{g} / \mathrm{g}$ ADW) in BL. However, this is not significantly different when measured on a protein basis according to one-way ANOVA and Duncan Test.

The significant difference in MDA content in NL and BL was highlighted in Figure 4. There was a statistically significant difference in MDA content between NL and BL extracts on both ADW and protein basis. MDA content decreased dramatically from $4.7 \pm 0.89(\mathrm{nmol} / \mathrm{g} \mathrm{ADW})$ or $2.3 \pm 0.53(\mathrm{nmol} / \mathrm{g}$ $\mathrm{ADW})$ to $2.53 \pm 0.4(\mathrm{nmol} / \mathrm{mg}$ protein $)$ or $1.09 \pm 0.23$ (nmol/mg protein).
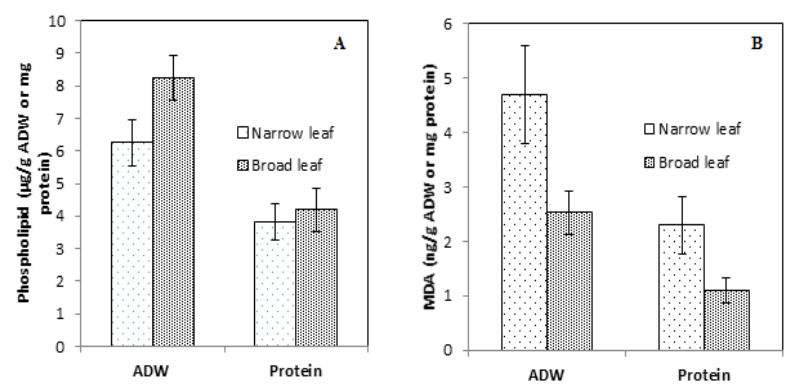

Figure-4. Phospholipid (A) and MDA (B) content on a protein basis and a dry weight basis in NL and BL extracts. Mean values $\pm(n=8)$. Data and results were based on one-way ANOVA and Duncan Test.

\section{Discussion}

Protein content in $C$. hindsii determined by a commercial assay kit (Bio-Rad) showed an elevated level in BL. It was higher than soluble protein content in leaves of chives (Allium schoenoprasum) cultivated plant, which contains less than $2 \mathrm{mg} / \mathrm{g}$ protein regardless of ADW or DW (Stanjner et al., 2011). The higher level of protein in BL in this study may be due to the significant difference in thickness of BL leaves, which may contain more amounts of proteins so that plants can perform better in growth and development. The most crucial role of the cell proteins is an enzymatic activity that catalyzes each reaction step in the biosynthesis pathways. Other proteins play vital roles in signaling transduction that controls the expression of genes in the nucleus by forming complexes with a nucleic acid that are regulatory functioning (Sjuts et al. 2017). Therefore, the higher protein content in BL indicated that this phenotype might perform better for physiological functions, and further proteomic study should be implemented to understand the mechanism hidden under this variation. Information about proline concentration has been limited in previous in vivo studies on $C$. hindsii and related medicinal plant species but varies among other medicinal plants in in vitro studies, which investigated the relationship of proline levels with other phytohormones and oxidative stresses. Proline can affect both positively and negatively by interaction with other phytohormones under stress (Iqbal et al., 2014). According to Manjili et al. (2012), salinity stress decreased the activity and proline content and other antioxidant enzymes of various wheat cultivars. It is suspected that other phytohormones probably regulated proline accumulation variation between NL and BL of $C$. hindsii under either specific oxidative stress or by total effect of adverse environmental conditions. Also, most of the above studies were conducted in in vitro conditions, which is usually not consistent with in vivo studies because of their different levels of controlled abiotic conditions. Therefore, the upregulated level of proline in NL may be contributed by some internal factors, such as leaf characteristics.

Glutathione (GSH) is widely considered as an indicator of oxidative stress in plants, although its role in plant metabolism is a multifaceted one (WujeskaKlause et al., 2015). GSH is one of the most crucial metabolites in plants. It plays a vital role in the antioxidant defense system against ROS induced oxidative damage. However, the concentration of cellular GHS greatly varies under abiotic stresses and considerably contributes to its antioxidant function. Recent studies have confirmed that the concentration of GSH increases in plants exposed to cadmium (Sobrino-plata et al., 2014), drought (Samuilov et al., 2016), and heat stress (Wujeska-Klause et al., 2015). In contrast, an increased level of GSH did not enhance resistance to $\mathrm{Cd}$ tress, and cold pre-treatment caused a slight decrease in the glutathione pools of Dunnaliella viridis (Madadkar et al., 2014). In this study, the similarity of GSH content between NL and BL of $C$. hindsii may indicate that GSH might not associate with stresses occurred in the two cultivars. In 
comparison with leaves of Allium schoenoprasum cultivated plants (Stanjner et al., 2011), the GSH quantities in $C$. hindsii was much lower (with a maximum of $12.97 \mathrm{nmol} / \mathrm{mg}$ protein versus $11.76 \mathrm{x}$ $10^{3} \mathrm{nmol} / \mathrm{mg}$ protein in A. schoenoprasum).

$\alpha$-tocopherol as an independent antioxidant or in conjunction with other antioxidants plays an important role in response to stress (Miret and Munn, 2015). In this study, $\mathrm{NL}$ and $\mathrm{BL}$ of $C$. hindsii contained significantly different content of $\alpha$-tocopherol in their leaf tissues $(18.81 \pm 1.5$ vs $22.29 \pm 1.23 \mu \mathrm{g} / \mathrm{g}$ ADW, respectively). The maximum content of $\alpha$-tocopherol was found in the leaves of $C$. hindsii (roughly $0.00223 \%$ by ADW or $0.00531 \%$ by $\mathrm{DW}$ ) by colorimetry. Whereas, it was only $0.0053 \%$ in an $\alpha$ tocopherol-rich plant of Pistacia lentiscus var. chia (Kivcak and Akay, 2005), based on the dry weight. Therefore, the leaves of $C$. hindsii may be considered as a potential new source of vitamin E. $\alpha$-tocopherol was found to be the most durable antioxidant under all drying environment $(86.4 \%$ retention during oven drying) (Saini et al., 2014). In addition, the collection and preservation of all leaf tissues in the present study were conducted by the same condition on silica gel drying at $-80^{\circ} \mathrm{C}$ storage. As a result, the $\alpha$-tocopherol levels were perhaps affected slightly, and its different levels in NL and BL must be due to their natural conditions where they were cultivated.

A higher level of flavonoids accumulations was measured in BL compared to NL (23.16 mg/g ADW versus $18.75 \mathrm{mg} / \mathrm{g} A D W$ or $40.30 \mathrm{mg} / \mathrm{g} D W$ versus $\left.22.10 \mathrm{mg} / \mathrm{g} \mathrm{DW}^{1}\right)$. Due to BL and NL plants were in in vivo condition, the flavonoid differences between BL and NL may be contributed by both "performed" and "induced" sources. The flavonoid content in $C$. hindsii is relatively high compared to other medicinal plants (Table 1). However, due to analytical variation (e.g., extract solvents and standard reagents), these measurements can result in a broad range of differences in the amount of flavonoids (Banothu et al., 2017).

It is suspected that the greater exposure to sunlight is the main factor regulating the higher level of flavonoids accumulated in BL of $C$. hindsii. However, this assumption does not refuse the role of other biotic and abiotic stress, which probably occurred and associated with flavonoid accumulation level during the growth and development of the species.

Table-1. Total flavonoid content in some medicinal plants

\begin{tabular}{|l|c|c|}
\hline \multicolumn{1}{|c|}{ Species } & $\begin{array}{c}\text { Total flavonoid } \\
\text { content } \\
\text { (mg/g dry weight) }\end{array}$ & References \\
\hline Physalis minima & 90.64 & $\begin{array}{c}\text { Banothu et al., } \\
\text { (2017) }\end{array}$ \\
\hline $\begin{array}{l}\text { Amaranthus } \\
\text { acanthochiton }\end{array}$ & 4.10 & $\begin{array}{c}\text { Jiménez-Aguilar } \\
\text { and Grusak (2017) }\end{array}$ \\
\hline $\begin{array}{l}\text { Senna Mill }(4 \\
\text { species) }\end{array}$ & $29.50-77.37$ & $\begin{array}{c}\text { Tyagi and Agarwal } \\
\text { (2017) }\end{array}$ \\
\hline $\begin{array}{l}\text { Eichhornia } \\
\text { crassipes }\end{array}$ & 0.49 & $\begin{array}{c}\text { Asadi-Samani et } \\
\text { al., (2018) }\end{array}$ \\
\hline $\begin{array}{l}\text { Plantago } \\
\text { lanceolata }\end{array}$ & 18.28 & \\
\hline
\end{tabular}

This assumption is in agreement with Kanazawa et al., (2012) that the accumulation of flavonoids increased sharply in response to increased UV radiation. Flavonoids are seldomly produced in plants or organs grown in insufficient light condition because the genes encoding for chalcone synthase (CHS) (the main enzyme involved in flavonoid biosynthesis pathway) is strictly expressed under light exposed condition (Petrussa et al., 2013). Contributing to the significant role of flavonoids in response to stressful conditions, Ma et al. (2014) stated that these compounds have protective roles in plants which are exposed to drought as the increased total flavonoids accumulation after drought treatment in wheat leaves (Triticum aestivum). This accelerated level of flavonoids was also found the same in Reaumuria soongorica (Liu et al., 2013).

Lipid peroxidation is a natural metabolic process occurring in plant tissues. However, this process is induced by oxidative stresses and can cause damage integrity of the tissues, particularly the cell membrane, where it contains a majority of polyunsaturated fatty acids. These damages are followed by the disintegration of organelles, oxidation, and dysfunction of proteins (Farmer and Mueller, 2013). The presence of phospholipids are believed to be important to maintain the membrane stability and protection as they can influence lipid oxidation through a number of mechanisms, such as binding prooxidative metals and producing anti-oxidative compounds ( $\alpha$-tocopherol) (Xue et al., 2007).

${ }^{1}$ The content of flavonoid/dry weight was converted from ADW based on a percentage of water calculated from ADW of C. hindsii leaves which contained $42.53 \%$ water in BL and $15.14 \%$ in NL. 
Therefore, understanding the abundance of phospholipids in plant tissues is valuable to select better selections for conservation and plant utilization. In this study, phospholipids concentrations were observed in leaf tissues of $C$. hindsii, and the results revealed a significant difference in $\mathrm{BL}(8.23 \pm 0.69$ $\mu \mathrm{g} / \mathrm{g}$ ADW $)$ and $\mathrm{NL}(6.25 \pm 0.7 \mu \mathrm{g} / \mathrm{g}$ ADW $)$. Phospholipids were substantially increased in BL, indicating a better possibility of this group against lipid peroxidation in response to adverse environmental conditions.

Malondialdehyde (MDA) is the most frequently measured product of lipid peroxidation as a biomarker of stresses (Tsikas, 2017). In many plants, a higher concentration of MDA is generally regarded as elevated oxidative stress (Farmer and Mueller, 2013). MDA content in NL was measured almost two times higher than that in BL. Our finding indicates there was an elevated level of lipid peroxidation occurred in NL because of possible oxidative induced stresses. In other words, BL might function a greater role in the protection of leaf tissue membranes. This highlights the role of antioxidants, including phospholipids, which involve membrane protection to reduce the production of MDA (Lin et al., 2014). Recent studies have reported that in some plants, an elevated level of MDA in plants was responded to abiotic stresses. Slama et al. (2015) confirmed that insufficient water supply could lead to an escalation of MDA content in Sesuvium portulacastrum leaves. Drought increased MDA content and lipid peroxidation significantly in leaves and roots of Sesamum indicum L. (Suzuki et al., 2014). In the current study, comparing the MDA content of $\mathrm{Nl}$ and $\mathrm{BL}$ showed that the cell membrane of BL of $C$. hindsii was probably better protected under oxidative stresses by a higher amount of phospholipids.

\section{Conclusion}

This study showed the presence of non-enzymatic antioxidant compounds, such as proline, glutathione, $\alpha$-tocopherol, flavonoids and phospholipids. The content of these secondary metabolites (except proline) were higher in BL compared to NL of $C$. hindsii, indicated that BL should be the selected phenotype for conservation and development of medicinal plant cultivation. The current study has also demonstrated that $C$. hindsii is a potential medicinal plant source of phytochemicals that could contribute to human health. The phytochemicals constituents of this plant may be responsible for their efficacy in the treatment of several human diseases. More specifically, BL had a very high concentration of vitamin $\mathrm{E}$ and flavonoids compared to other rich sources of phytochemicals. Because this species adapts to a wide range of environments, their cultivation as medicinal sources should be encouraged for commercial purposes, especially in rural areas, where the local livelihood mostly rely on natural resources. Further work has to be carried out to isolate, purify, and characterize the phytochemicals of this plant responsible for bioactive properties as well as their molecular mechanisms.

\section{Acknowledgement}

The authors highly acknowledge the Ministry of Education and Training, Vietnam, for supporting this research study.

Disclaimer: None.

Conflict of Interest: None. Source of Funding: None.

\section{References}

Asadi-Samani M, Rafieian-Kopaei M, Lorigooini Z and Shirzad H, 2018. A screening to determine total phenol and flavonoid content of some iran's medicinal plants grown in chaharmahal va Bakhtyari province. Indian J. Nat. Prod. Resour. 9: 296-302.

Banothu V, Adepally UMA and Lingam J, 2017. In vitro total phenolics, flavonoids contents, antioxidant and antimicrobial activities of various solvent extracts from the medicianal plant Physalis minima Linn. Int. J. Pharm. Sci. 9: 192198.

Bates LS, Waldren RP and Teare ID, 1973. Rapid determination of free proline for water-stress studies. Plant Soil. 39: 205-207.

de la Cruz Jiménez J, Kotula L, Veneklaas EJ and Colmer TD, 2019. Root-zone hypoxia reduces growth of the tropical forage grass Urochloa humidicola in high-nutrient but not low-nutrient conditions. Ann. Bot. 124: 1019-1032.

Farmer EE and Mueller MJ, 2013. ROS-Mediated Lipid Peroxidation and RES-Activated Signaling. Annu. Rev. Plant Biol. 64: 429-450. 
Fichman Y, Miller G and Mittler R, 2019. Whole-plant live imaging of reactive oxygen species. Mol. Plant. 12: 1203-1210.

Forman HJ, Zhang H and Rinna A, 2009. Glutathione: Overview of its protective roles, measurement, and biosynthesis. Mol. Aspects Med. 30: 1-12.

Fu JE, Feng L, Wei SG, Ma XJ, Huang RS, Feng SX, Dong QS and Yan ZG, 2016. Distinctive morphological characteristics contribute to the identification of Artemisia annua L. germplasms with high yield and high artemisinin content. J. Appl. Res. Med. Aromat. Plants. 3: 43-47.

Hu X-Q, Han W, Han Z-Z, Liu Q-X, Xu X-K, Fu P and $\mathrm{Li} \mathrm{H}-\mathrm{L}, 2014$. A new macrocyclic lactone and a new quinoflavan from Celastrus hindsii. Phytochem. Lett. 7: 169-172.

Hu XQ, Han W, Han ZZ, Liu QX, Xu XK, Fu P and Li HL, 2013. Three new diphenylpropanes from Celastrus hindsii. Arch. Pharm. Res. 37: 1411-5.

Iqbal N, Umar S, Khan NA and Khan MIR, 2014. A new perspective of phytohormones in salinity tolerance: Regulation of proline metabolism. Environ. Exp. Bot. 100: 34-42.

Jiménez-Aguilar DM and Grusak MA, 2017. Minerals, vitamin $\mathrm{C}$, phenolics, flavonoids and antioxidant activity of Amaranthus leafy vegetables. J. Food Compos. Anal. 58: 33-39.

Kamiloglu S, Toydemir G, Boyacioglu D, Beekwilder J, Hall RD and Capanoglu E, 2016. A Review on the effect of drying on antioxidant potential of fruits and vegetables. Crit. Rev. Food Sci. Nutr. 56: 110-129.

Kanazawa K, Hashimoto T, Yoshida S, Sungwon P and Fukuda S, 2012. Short photoirradiation induces flavonoid synthesis and increases its production in postharvest vegetables. J. Agric. Food Chem. 60: 4359-4368.

Khanna PK, Chandra R, Kumar A, Dogra N, Gupta H, Gupta G and Verma V, 2014. Correlation between morphological, chemical and RAPD markers for assessing genetic diversity in Withania somnifera (L.) Dunal. J. Crop Sci. Biotech 17: 27-34.

Kivcak B and Akay S, 2005. Quantitative determination of a -tocopherol in Pistacia lentiscus, Pistacia lentiscus var. chia, and Pistacia terebinthus by TLC-densitometry and colorimetry. Fitoterapia. 76: 62-66.

Lin F, Qu Y and Zhang Q, 2014. Phospholipids molecules regulating cytoskeletal organization in plant abiotic stress tolerance. Plant Signal. Behav. 9: e28337-1- e28337-5.
Liu ME, Liao YC, Lin RT, Wang YS, Hsi E, Lin HF, Chen KC and Juo SHH, 2013. A functional polymorphism of PON1 interferes with microRNA binding to increase the risk of ischemic stroke and carotid atherosclerosis. Atherosclerosis. 228: 161-167.

Ly TN, Shimoyamada M and Yamauchi R, 2006. Isolation and characterization of rosmarinic acid oligomers in Celastrus hindsii Benth leaves and their anti-oxidative activity. J. Agric. Food Chem. 54: 3786-93.

Ma D, Sun D, Wang C, Li Y and Guo T, 2014. Expression of flavonoid biosynthesis genes and accumulation of flavonoid in wheat leaves in response to drought stress. Plant Physiol. Biochem. 80: 60-66.

Madadkar M, Colville L and Smirnoff N, 2014. The induction of menadione stress tolerance in the marine microalga, Dunaliella viridis, through cold pre-treatment and modulation of the ascorbate and glutathione pools. Plant Physiol. Biochem. 84: 96-104.

Manjili FA, Sedghi M and Pessarakli M, 2012. Effects of phytohormones on proline content and antioxidant enzymes of various wheat cultivars under salinity stress. J. Plant Nutr. 35: 1098-1111.

Mediavilla S, García-Cunchillos I, Andrés-Rivera C and Escudero A, 2018. Losses of leaf area owing to abiotic stress along the leaf economics spectrum: implications for carbon gain at the branch level. Trees. 32: 559-569.

Miret JA and Munn S, 2015. Redox signaling and stress tolerance in plants: a focus on vitamin E. Ann. N. Y. Acad. Sci. 1340: 29-38.

Morina F, Milić S and Jovanović SV, 2015. An improved HPLC-DAD method for simultaneously measuring phenolics in the leaves of Tilia platyphyllos and Ailanthus altissima. Bot. Serbica 39: 177-186.

Nagayama T, Nakamura A, Yamaji N, Satoh S, Furukawa $\mathrm{J}$ and Iwai H, 2019. Changes in the distribution of pectin in root border cells under aluminum stress. Front. Plant Sci. 10: 1-8.

Nakabayashi $\mathrm{R}$ and Saito K, 2015. Integrated metabolomics for abiotic stress responses in plants. Curr. Opin. Plant Biol. 24: 10-16.

Petrussa E, Braidot E, Zancani M, Peresson C, Bertolini A, Patui S and Vianello A, 2013. Plant flavonoids-biosynthesis, transport and involvement in stress responses. Int. J. Mol. Sci. 14: 14950-14973. 
Purugganan MD, 2019. Evolutionary insights into the nature of plant domestication. Curr. Biol. 29: R705-R714.

Saini RK, Shetty NP, Prakash M and Giridhar P, 2014. Effect of dehydration methods on retention of carotenoids, tocopherols, ascorbic acid and antioxidant activity in Moringa oleifera leaves and preparation of a RTE product. J. Food Sci. Technol. 51: 2176-2182.

Samuilov S, Lang F, Djukic $M$ and Djunisijevicbojovic D, 2016. Lead uptake increases drought tolerance of wild type and transgenic poplar (Populus tremula x P. alba) overexpressing gsh $1^{*}$. Environ. Pollut. 216: 773-785.

Sharma R and Kaur R, 2018. Insights into fluorideinduced oxidative stress and antioxidant defences in plants. Acta Physiol. Plant. 40: 181.

Sjuts I, Soll J, Bölter B, Smith MD and Rolland V, 2017. Import of soluble proteins into chloroplasts and potential regulatory mechanisms. Front. Plant Sci. 8: 1-15.

Slama I, M'Rabet R, Ksouri R, Talbi O, Debez A and Abdelly C, 2015. Water deficit stress applied only or combined with salinity affects physiological parameters and antioxidant capacity in Sesuvium portulacastrum. Flora Morphol. Distrib. Funct. Ecol. Plants 213: 69-76.

Sobrino-plata J, Carrasco-gil S, Abadi J and Escobar $\mathrm{C}, 2014$. The role of glutathione in mercury tolerance resembles its function under cadmium stress in Arabidopsis. Metallomics. 6: 356-366.

Stanjner D, Popovi BM, Dragosavac DC, Malencic D and Zdravkovic S, 2011. Comparative study on Allium schoenoprasum cultivated plant and Allium schoenoprasum tissue culture organs antioxidant status. Phytother. Res. 1622: 1618-1622.

Suzuki N, Rivero RM, Shulaev V, Blumwald E and Mittler R, 2014. Abiotic and biotic stress combinations. New Phytol. 203: 32-43.

Swain $T$ and Hillis WE, 1959. The phenolic constituents of Prunus domestica. I. The quantitative analysis of phenolic constituents. J. Sci. Food Agric. 10: 63-68.

The Asian Foundation, 2012. Medicinal plant index of the Daos in Ba Vi. Cong ty Truyen thong ICON, Hanoi.

Tsikas D, 2017. Assessment of lipid peroxidation by measuring malondialdehyde (MDA) and relatives in biological samples: Analytical and biological challenges. Anal. Biochem. 524: 13-30.

Tyagi T and Agarwal M, 2017. Antioxidant properties and phenolic compounds in methanolic extracts of Eichhornia crassipes. Res. J. Phytochem. 11: 85-89.

Wujeska-Klause A, Bossinger G and Tausz M, 2015. Responses to heatwaves of gas exchange, chlorophyll fluorescence and antioxidants ascorbic acid and glutathione in congeneric pairs of Acacia and Eucalyptus species from relatively cooler and warmer climates. Trees Struct. Funct. 29: 1929-1941.

Xue H, Chen X and Li G, 2007. Involvement of phospholipid signaling in plant growth and hormone effects. Curr. Opin. Plant Biol. 10: 483489.

Yao-Haur Kuo, Chen C-F and Kuo L-MY, 1995. Celahinine a, a new sesquiterpene pyridine alkaloid from Celastrus hindsii. J. Nat. Prod. 58: 1735-1738.

\section{Contribution of Authors}

Nguyen VH: Developed the theory, designed the experiments, gave guidance on data analysis and wrote the manuscript

Pham TL: Carried out the experiments, verified the experimental methods and analyzed the data Nguyen QT: Carried out the experiments, verified the experimental methods and analyzed the data 